\title{
Civilian - military interferences in the management of research for the security and defense field
}

\author{
Dorel Badea ${ }^{1, *}$, Gabriel Mănescu ${ }^{1}$, Dumitru Iancu ${ }^{1}$, Olga Bucovețchi ${ }^{2}$, and Anca Dinicu ${ }^{3}$ \\ 1"Nicolae Bălcescu” Land Forces Academy, Department of Management, Sibiu, Romania \\ ${ }^{2}$ Polytechnic University of Bucharest, Department of Economic Engineering, Bucharest, Romania \\ 3"Nicolae Bălcescu" Land Forces Academy, Department of Military Sciences, Sibiu, Romania
}

\begin{abstract}
Changes in the security spectrum, in terms of reconfiguring its military content, subsequently involves another approach to security and defense research. Especially the economic aspects have a quantitative and qualitative impact on the management of the research specific to this field, which has long been taken for granted, causing changes in both the interests and the power of influence held by different categories of stakeholders. This article explores the main directions of change within the aforementioned framework, highlighting the major modalities of involving the civilian segment of capabilities and specialized assets, on a track considered for a long time and to a much greater extent compared to the present imperatives, as an area dedicated exclusively to the military. The thematic target approached by the team of authors includes both national and international plans, individualized or clustered, at the current level but also as trends, the main aim of the scientific approach is that of highlighting good practices in the field of research and development of dual-use products. The conclusion is that the possibilities of the civilianmilitary academic cooperation can be better grounded in order to achieve better results in terms of the operationalization of the security interest in a comprehensive manner, materialized mainly through research projects.
\end{abstract}

\section{Introductory considerations}

As stated in the abstract, in line with the current evolution of society and the reconsideration of the primordial values of humanity as a whole, and scientific research as a process, it has to rely on the new trends (for example industry 4.0) and meet the new necessities. In fact, in a wider register, the adaptive-dynamic flexibility, the principle of conscious change of perspective education, which was enacted in the late 1990s by J. Mezirow [1] aimed at restructuring the value system in which the individual can critically analyze the social role, redefining it through new aspirations and experiences, is more relevant than ever. Subsequently, in the field of security and defense, the following features

\footnotetext{
* Corresponding author: dorel.badea@yahoo.com
} 
are increasingly manifested: enough NGOs, non-militarized institutions have as subjects of interest major themes of security, bringing the civil perspective as added value; after retirement, part of the security and defense leaders become employees of such organizations, contributing to the comprehensive research and understanding of issues on the public agenda regarding security and defense; there is an acceleration of the „privatization of security” against the background of the aforementioned aspects; the technological vector, which also characterizes the military dimension of security, changes the way of doing research, determining the approach of large-scale, interdisciplinary themes with the use of highly scientific instruments; security studies are addressed not only at military universities but also in civilian universities, the soft component, human security being increasingly investigated in the latter, which focuses on the individual as an exponent of the society to which he belongs, in close relationship with complex concepts such as human development and sustainability.

The research itself is increasingly high tech, both as a process and as a tool used, the standards in the field of project and program management facilitating, at least by creating a common working vocabulary, the internalization of development opportunities manifested at macro level (What type of system, process, phenomenon is the one approached and what purpose does it satisfy? How predictable is the evolution of its state? What does the system, process, phenomenon bring to improve the situation of the main categories of stakeholders?). The idea is supported starting from the conceptualization of the R\&D function of the organizations [2], with the activities of research and technological development, the introduction of technical progress, the assimilation of new products, the development of resources through investments and managerial redesign, as follows: the activities which take place within the organization, in order to achieve the goals of new ideas and the transformation of ideas into useful novelty in the future. From the general management theory, we stress upon and bring additional comments to the customization of the proposed subject, namely: the idea of the utility of the solutions, the principle of compatibility between the mechanisms of management achievement and the general characteristics of the internal research, and last but not least, the structuring of the main aspects of scientific research management (organizational, informational, decision-making and management).

Specifically, topics and research in the field of space, artificial intelligence, biotechnology, nuclear applications etc. no longer have as much intensity and volume of approach exclusive outcomes in industries specific to products in the security and defense industries, the center of gravity moving towards usability for a wide range of uses, including those of a civilian character, especially for solving some topical issues, of global interest, occupying a special place.

The overview of the most important organizational approaches (in relation to the target deliverables) of the subject brings us to the issues presented below.

At NATO level, there is the Science for Peace and Security (SPS) Program [3] which "connects scientists, experts and officials from Allied and partner countries to address security challenges, such as cyber defence, counter-terrorism or defence against CBRN agents; to support NATO-led missions and operations; to foster the development of security-related advanced technologies such as sensors and detectors, nanotechnologies, unmanned aerial vehicles (UAVs); and to address human and social aspects of security such as the implementation of United Nations Security Council Resolution 1325 on Women, Peace and Security (UNSCR 1325)."In support of the current issue, it is worth mentioning the words of Rose Gottemoeller (NATO Deputy Secretary General) who, at the 60 $0^{\text {th }}$ anniversary of the SPS (November 2018) stated: "It is science that provides our understanding of emerging security challenges, and it's science that will underpin our solutions" [4]. 
At EU level [5], major social concerns, such as climate change, sustainable transport, renewable, energy, food safety and security objectives are envisaged, and the Horizon 2020 research program specifies that "mission-oriented actions will integrate the demands of different end-users (citizens, businesses, civil society organisations and administrations, including national and international authorities, civil protection, law enforcement, border guards, etc.) in order to take into account the evolution of security threats and privacy protection, and the necessary societal aspects." [6], among the main effort lines being mentioned: "protect and improve the resilience of critical infrastructures, supply chains and transport modes; strengthen security through border management; improve cyber security; increase Europe's resilience to crises and disasters; ensure privacy and freedom, including in the Internet, and enhance the societal legal and ethical understanding of all areas of security, risk and management; enhance standardisation and interoperability of systems, including for emergency purposes" [6].

\section{Managerial challenges of dual-use product development}

The interdependence between security and defense must be seen as a relationship between the proximity gender and the specific difference, the society as a whole being both a beneficiary and an operational part that can create through research a minimum level of functional acceptability to create the conditions for development and evolution. In this respect, the approach of authors Katarina Wilhelmsen and Mikael Wiklund is relevant, which mentions: "Defence and security research plays a vital role in building the capability and readiness needed to ensure our national security, since accessible knowledge defines the limits of both military operational capability and society's general preparedness.[...] An issue of national security often originates as an issue of defence, infrastructure or foreign policy and then gains in significance as an issue of national security after it has intersected with other policy spheres" [7].

The idea of cooperation between the civilian and the military sectors is not new, the coordinates that are being developed are others (more flexibility compared to the post-cold war period, for example). An approach to general objectives similar to this article is found in the report by ECORYS, which states that "in the present context a civil-military synergy implies a greater effectiveness or efficiency, achieved through combined actions or cooperation between the civil security and the military sectors than would or could be achieved separately" [8].

All major scientific and technical achievements have been directly or indirectly aimed at civilian or eminently military purposes. As a peculiarity, the great discoveries in the military field have been transferred to the civilian field only after it has been assumed that they have achieved their goals and objectives for which they have been developed, have passed the stage of full maturity and are about to exhaust their resources or the benefits they bring on a global scale can later contribute to the sustainable development of all areas of social and economic life.

The most eloquent example in the latter case is the Internet, the concept of wide area networking being developed in the early 1960s within the ARPANET project (Research Projects Agency Network), project initially funded by U.S. Department of Defense. Achieving its goals and making a significant contribution to the development of the Internet protocol suite (TCP/IP - the standard networking protocol on the ARPANET), the project is officially closed 30 years later, not before ensuring the connectivity with the NSFNET project (since 1986). The last barrier to including the Internet in the commercial circuit (and launching it at global level) took place in 1995 with the closure of the NSFNET project. About the advantages of the Internet and the role that it has and will have in the development of humanity has been spoken and will be talked about for a long time now. 
Currently, one of the dual-use technologies, with one of the highest developmental paces, is that of UAVs. The origins of the UAV go back a few centuries when simple hot air balloons were used to carry small explosive loads over enemy fortifications. Today, UAVs (or drones as they are commonly known) use artificial intelligence, being able to make certain decisions independently, their evolution being shown in figure no. 1.

Due to the almost unlimited possibilities for the use of certain products or technologies, the greatest danger being the use in terrorist actions, the decision was made at international level to strictly regulate the conception, development and use of these types of products and technologies.

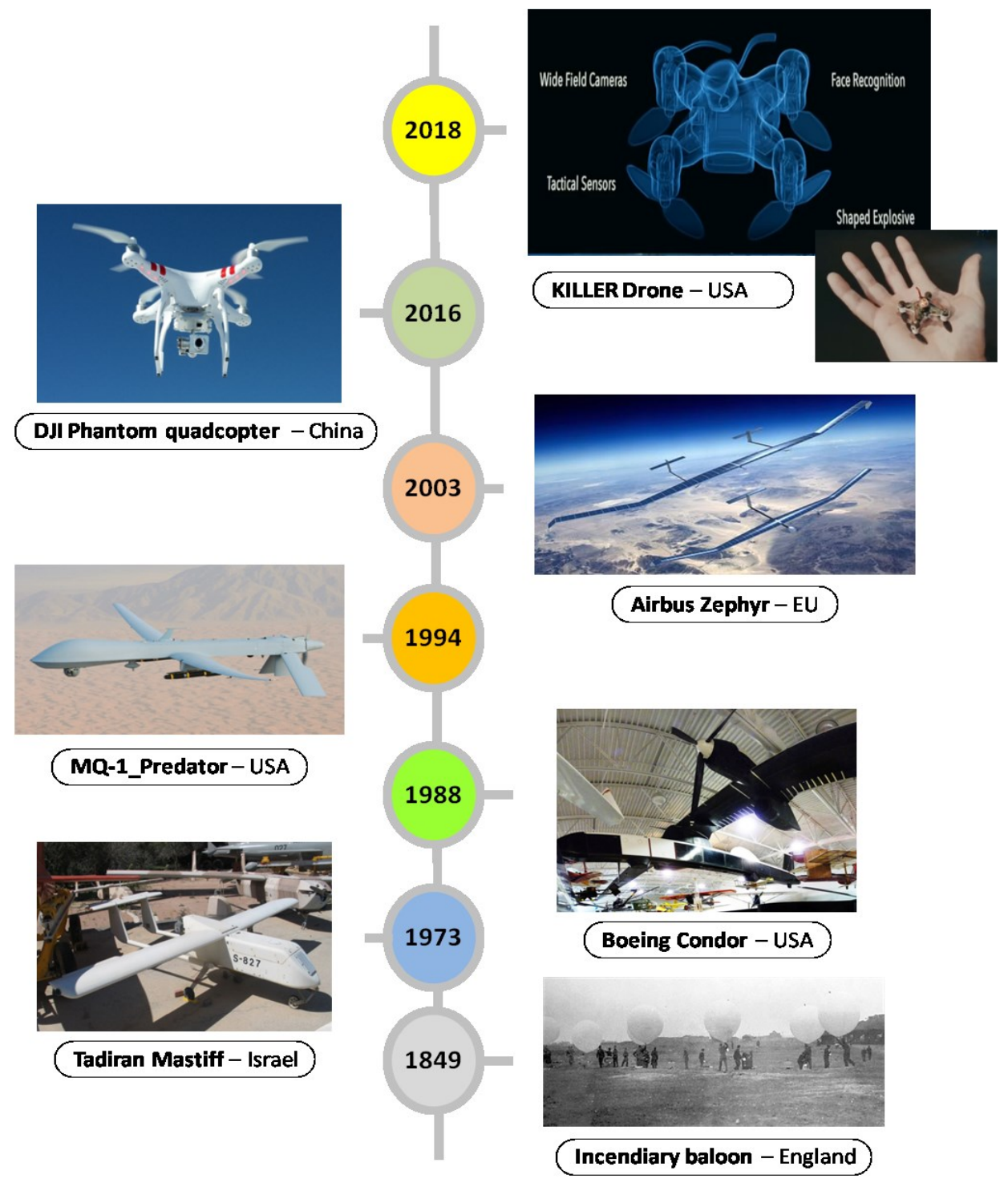

Fig. 1. Brief history of UAV's development (Photo source: [9 -15]).

Finding an unequivocally unambiguous definition, the features, the possible areas in which they can be used, and the influence/impact that products and technologies with 
multiple uses can have on any life and the environment has been a long process. The link between this concept and weapons of mass destruction is made in a report from the 1993 US Office of Technology Assessment - "understanding the extent to which 'dual use' technologies or products - those also having legitimate application-are involved in the development of weapons of mass destruction is important, since both the feasibility of controlling dual-use items and the implications of doing so depend on the extent of their other applications" [16].

This definition has been used for over two decades to signal the dual applicability, civilian and military, of certain products, technologies and even services.

Today, according to Council Regulation (EC) No 428/2009 'dual-use items' are defined as "items, including software and technology, which can be used for both civil and military purposes, and shall include all goods which can be used for both non-explosive uses and assisting in any way in the manufacture of nuclear weapons or other nuclear explosive devices" [17].

In order to prevent the production of goods for commercial use which consist of elements (chemical and/or physical) made as separate components, as sub-assemblies or as a whole, but which may be applicable in the military field or which may contribute to the production of components or even on weapons with potential for mass destruction, an internationally agreed list of dual-use items has been drawn up for the export, transfer, brokering and transit of dual use items.

An example of setting codes for dual-use items, taking into account the category of goods, the type of product and the regime of their use are shown in figure no. 2.

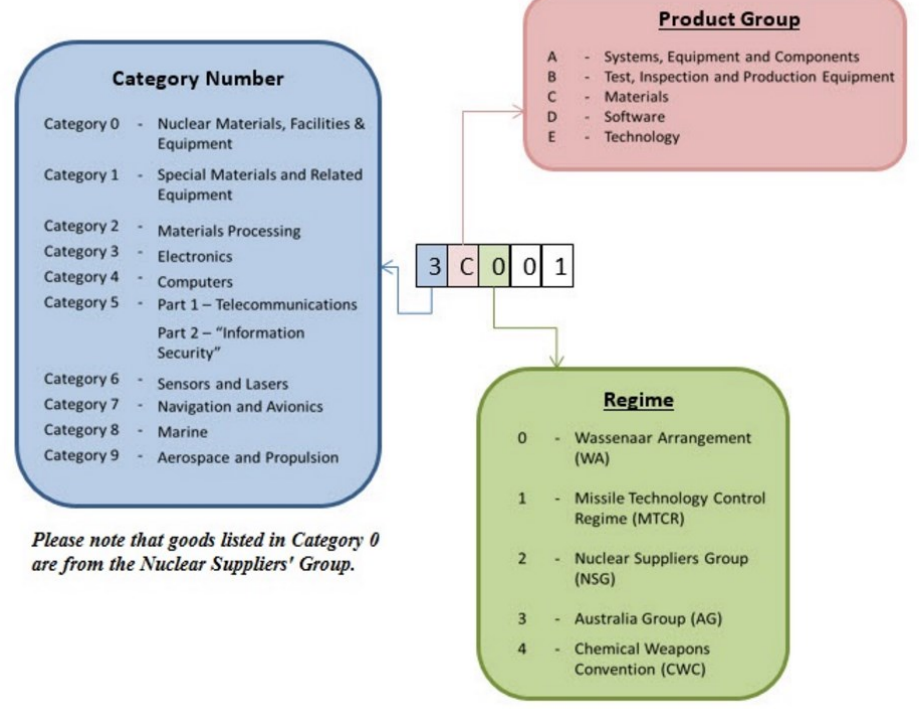

Fig. 2. The alphanumeric code used for items and technology in the List of Dual-Use items [18]

Another crucial milestone in controlling and managing capabilities, civilian and military sectors, designing and achieving dual-use items was the regulation of issues related to dualuse research.

The collaboration of all entities with research capabilities, both civilian and military, as well as the full involvement of stakeholders is essential for the proper management of all resources allocated to this type of research, the first aim of which is to develop new 
solutions, products and services with dual use. The following figure shows the interdependencies between stakeholders' involved in dual use research.

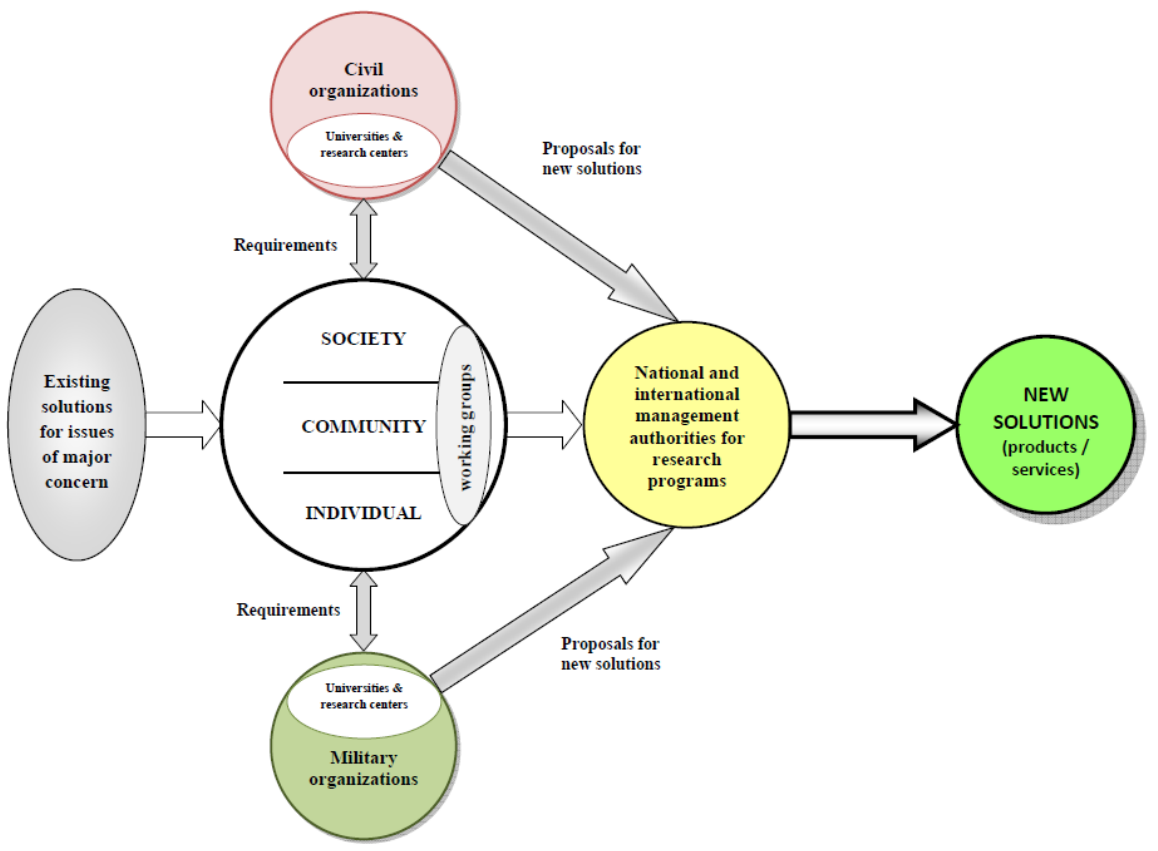

Fig. 3. The interdependencies between stakeholders' involved in dual use research

The concept of dual-use research in turn has many meanings. From the perspective of our study, we believe that the most explicit definition is that of the National Science Advisory Board for Biosecurity (NSABB) from 2007 which broadens the scope of dual-use to include a number of purposes and of misuses other than military: "research that, based on current understanding, can be reasonably anticipated to provide knowledge, products, or technologies that could be directly misapplied by others to pose a threat to public health and safety, agriculture, plants, animals, the environment, or material" [16].

Of course, the definition has generated many questions related, in general, to legality issues or the moral boundaries of the concept. Such questions have focused on issues like “current understanding, reasonably anticipated, 'and 'directly misapplied' opens doors to many publications that would otherwise qualify for a special review" [16].

"Misuse of research" is to be understood as "research that could be misused for unethical purposes" [19].

The research most vulnerable to misuse is research that:

- "provides knowledge, materials, methods and technologies that could be channelled into crime or terrorism;

- could result in chemical, biological, radiological or nuclear weapons and the means for their delivery;

- involves developing surveillance technologies that could curtail human rights and civil liberties;

- involves minority or vulnerable groups or develops social, behavioural or genetic profiling technologies that could be misused to stigmatize, discriminate against, harass or intimidate people" [19]. 
It is precisely because of the dual-use research vulnerabilities, but also research-related products and technologies, whose uncontrolled use can easily be used in terrorist attacks or can fit into totalitarian regimes at international level, measures have been taken to prevent, control and stop the transfer of dual-use products and technologies. In this sense, each entity carrying out dual-use research must determine "whether a product is a dual-use item, the technical specifications of the items must be verified against the descriptions in the list of dual-use items" [19].

\section{Enhance the competitiveness of dual-use items and dual-use research}

Today, due to multiple interconnections between civilian and military sectors, it is almost impossible to achieve a separation line. The defense industry is increasingly dependent on scientific and technological performance of civilian origin while the latter, in order to strengthen their position in a market dominated by state-of-the-art technologies, are interested in purchasing products and technologies that can be converted for civilian use.

Against this background, at the European Council meeting in December 2013, "the potential of $R \& D$ products and services was emphasized once again, and the firm involvement of small and medium-sized enterprises in defense in the future financing programs" [20].

One of the ways in which dual-use items and dual-use research can contribute to the economic development of the regions and facilitate civilian-military cooperation is that of clusters.

Therefore, "each type of cluster will have to find its own rationale to identify its assets and competitive advantages to engage in dual-use diversification and to lobby its regional or national policymakers to provide them with the right type of public support to be successful in such an exercise" [20]. The following figure shows the potential for dual-use inter-clustering action.

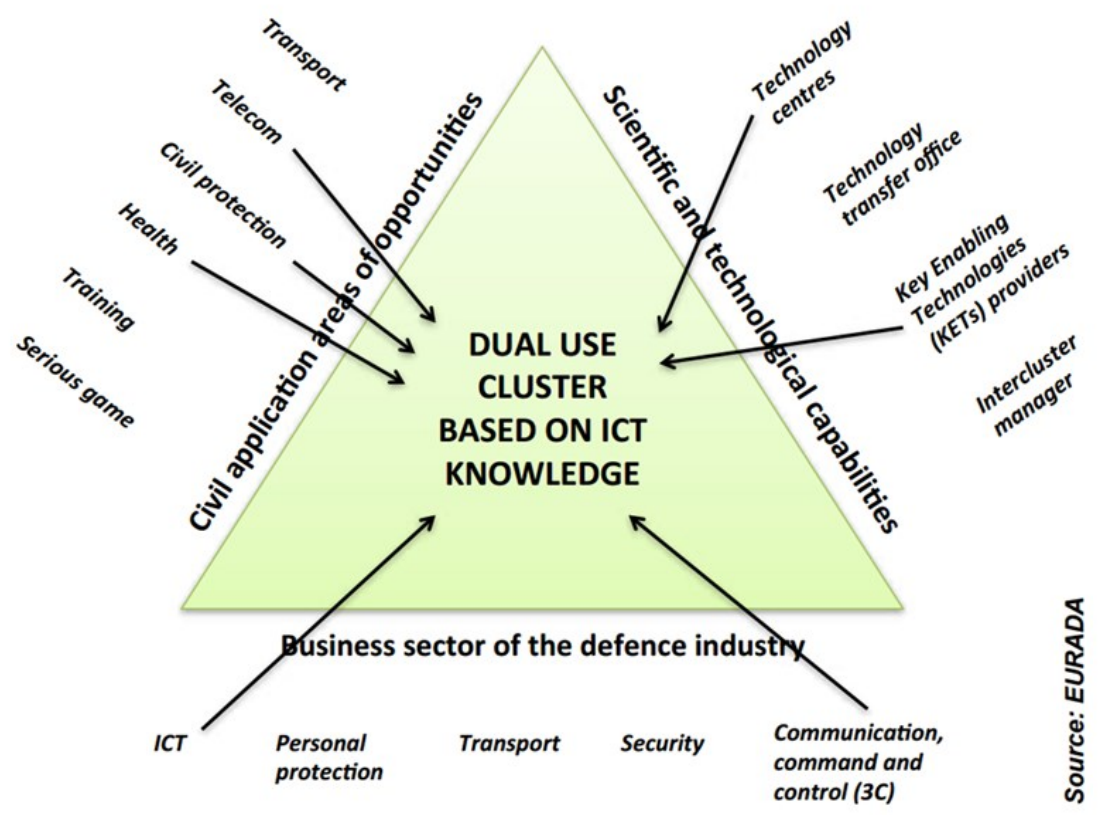

Fig. 4. The potential for dual-use inter-clustering action [20] 


\section{Conclusion}

Scientific research is a predominantly collaborative activity and the mechanisms governing this activity should stimulate collaboration between scientists, security experts and the general public. The best policies in the field of dual-use items and dual-use research will result from efforts to promote a culture of shared responsibility between civilian and military stakeholders, policies that will have to maintain public trust and support through an active commitment to the sources of concern generated by how authorities are able to manage potential risks.

In addition to the safe use of these products, public authorities should be more involved in developing dual-use strategies that are an integral part of Smart Specialization Development Strategies, especially when institutional committees need help in accessing or spreading potential risks.

\section{References}

1. Mezirow, J., Perspective Transformation, în Studies in Adult Education, Leicester, 9, nr.2, pp.153-161 (1987)

2. E. Burduş, Tratat de management, (Editura ProUniversitaria, București, 2012)

3. https://www.nato.int/cps/en/natohq/topics 85373.htm (accessed on Feb. 20, 2019)

4. https://www.nato.int/cps/en/natohq/news 160936.htm (accessed on Feb. 20, 2019)

5. https://europa.eu/european-union/topics/research-innovation en (accessed on Feb, 20, 2019)

6. https://ec.europa.eu/programmes/horizon2020/en/area/security (accessed on Feb, 20, 2019)

7. K. Wilhelmsen, M. Wiklund, The Significance of Defense Research for National Security ( FOI Memo 6197. Offprint from Strategic Outlook 7), available at https://www.foi.se/report-search/pdf?fileName...e3cd, (accessed on Feb. 21, 2019)

8. ***ECORYS, Study on Civil Military Synergies in the field of Security-Final Report, Rotterdam, May 2012, available at at https://ec.europa.eu/home-affairs/sites/homeaffairs/files/elibrary/documents/policies/security/pdf/study ecorys cimisos final report en.pdf, (accessed on Feb. 21, 2019)

9. https://en.wikipedia.org/wiki/Incendiary balloon, (accessed on Feb. 15, 2019)

10. https://www.revolvy.com/page/Tadiran-Mastiff, (accessed on Feb. 15, 2019)

11. https://www.flickr.com/photos/seat850/3028319135/, (accessed on Feb. 15, 2019)

12. https://en.wikipedia.org/wiki/General_Atomics_MQ-1_Predator, (accessed on Feb. 15, 2019)

13. https://en.wikipedia.org/wiki/Airbus Zephyr, (accessed on Feb. 15, 2019)

14. https://www.youtube.com/watch?v=T1O2gcs1YvM, (accessed on Feb. 15, 2019)

15. https://en.wikipedia.org/wiki/Phantom (UAV), (accessed on Feb. 15, 2019)

16. Al. Dubov, The concept of governance in dual-use research, (2007), available at https://www.researchgate.net/publication/259809278 The concept of governance in dualuse research, (accessed on. Jan.15, 2019)

17. The Council of the European Union, Council Regulation (EC) No 428/2009, available at https://eur-lex.europa.eu/LexUriServ/LexUriServ.do?uri=OJ:L:2009:134:0001:0269:en:PDF, (accessed on. Jan.17, 2019)

18. https://www.customs.gov.sg/businesses/strategic-goods-control/strategic-goods-control-list/listof-dual-use-goods

19. Guidelines for researchers on dual use and misuse of research, (2017), available at: https:/www.uhasselt.be/documents/DOC/2017VLIR003 FolderOnderzoek_EN_DEF 20180212 .pdf, (accessed on. Feb.02, 2019)

20. European Commission, EU funding for Dual Use, available at: https:/www.czelo.cz/files/EUfunding-for-Dual-Use-Guidebook-2-.pdf. accessed on. Jan.15, (2019) 